\title{
Numerical simulation of SARS-CoV-2 by SKAZI scheme
}

\author{
Sadaqat $\operatorname{Ali}^{1}$ \\ ${ }^{1}$ The University of Lahore - Gujrat Campus
}

April 28, 2020

\begin{abstract}
In this paper, we present the mathematical model for severe acute respiratory syndrome coronavirus 2 (SARS-CoV-2). The outbreak of SARS-CoV-2 has led to 2,192,469 confirmed cases as of April 17, 2020 and total deaths are 147,360 in 210 different countries, area or territories. The basic reproductive number is formulated using next generation approach. The sensitivity analysis of reproductive number and local stability analysis of mathematical model are discussed. Also, we present numerical approximations for the disease free and endemic equilibrium points for infection of SARS-CoV-2. Also, we propose an efficient SKAZI scheme. Lastly, we present numerical experimentation of SKAZI scheme. The disease free and endemic equilibrium points are graphical reveal for stability and instability of mathematical model.
\end{abstract}

\section{Hosted file}

Paper.pdf available at https://authorea.com/users/312843/articles/443404-numerical-simulationof-sars-cov-2-by-skazi-scheme 